\title{
Hypertrichosis lanuginosa congenita
}

INSERM

\section{Source}

INSERM. (1999). Orphanet: an online rare disease and orphan drug data base.

Hypertrichosis lanuginosa congenita. ORPHA:2222

Hypertrichosis lanuginosa congenita is a rare congenital skin disease characterized by the presence of 3 to $5 \mathrm{~cm}$ long lanugo-type hair on the entire body, with the exception of palms, soles, and mucous membranes. 